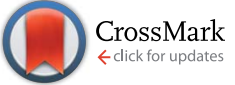

Cite this: RSC Adv., 2016, 6, 69984
Received 7th April 2016

Accepted 15th July 2016

DOI: 10.1039/c6ra09013c

www.rsc.org/advances

\section{Crosslinked polymeric self-assemblies as an efficient strategy for photodynamic therapy on a 3D cell culture $\uparrow$}

\author{
Ugo Till, ${ }^{\text {ab }}$ Laure Gibot, ${ }^{c}$ Patricia Vicendo, ${ }^{b}$ Marie-Pierre Rols, ${ }^{c}$ Mireille Gaucher, ${ }^{a}$ \\ Frédéric Violleau*de and Anne-Françoise Mingotaud ${ }^{\star b}$
}

In order to compare the efficiency of crosslinked nano-vectors in the field of photodynamic therapy (PDT) both on 2D and 3D cell cultures, various polymeric crosslinked self-assemblies based on poly(ethyleneoxide- $b-\varepsilon$-caprolactone) have been synthesized by radical polymerization of acrylate endfunctionalized polymers. Crosslinked self-assemblies obtained from the reaction of the functionalized polymers with ethyleneglycoldimethacrylate (EGDMA) were compared to chain-end polymerized and to unreacted ones. Polymeric micelles with a size between 10 and $20 \mathrm{~nm}$ were obtained, as well as an elongated system with a length close to $100 \mathrm{~nm}$. They all have been characterized by Transmission Electron Microscopy and Dynamic Light Scattering but also by Asymmetrical Flow Field-Flow Fractionation in order to prove that they consisted of pure self-assemblies. Chain-end polymerization or crosslinking did not induce any change in morphology nor strong size modification. After postencapsulation of a photosensitizer, namely Pheophorbide a, the systems have been examined for their potential use in PDT on HCT-116 and FaDu human tumor cell lines both in 2D and 3D cultures. The crosslinked vectors were observed to be the most efficient on both cell lines cultivated in 3D spheroids, whereas unreacted or chain-end polymerized ones presented a lower activity. This was different from the trend observed in 2D cell cultures where an uncrosslinked micelle was observed to be efficient at a lower concentration compared to its chain-end polymerized or crosslinked analogue. The different synthesized self-assemblies also allowed assessing the influence of polymer chain length and shape on PDT efficiency. The molecular weight of the polymer did not lead in our case to efficiency change, for similar size and surface characteristics. As for the shape effect, the elongated self-assembly was not observed in our case to be more efficient than spherical micelles. Crosslinked polymeric vectors are therefore promising vectors for $3 \mathrm{D}$ tumor treatment.

\section{Introduction}

Polymeric self-assemblies have been exceedingly studied for the last 30 years as nanovectors for biomedical applications, owing to their capacity to modify the biodistribution of drugs. ${ }^{1-8}$ The main application is linked to oncology, since nanovectors having a size range between 15 and $200 \mathrm{~nm}$ have been shown to accumulate passively in tumors owing to the enhanced permeability and retention effect (EPR). ${ }^{9-11}$ In order to be considered as valuable nanovectors, the self-assemblies have to fulfill several specifications: biocompatibility, good encapsulation of the drug but also controlled release (if possible time- and space-controlled), biodegradability or at least elimination by natural clearance after use. Thus, possible crosslinking of the polymer self-assemblies has been suggested and examined. Several strategies have been evaluated, namely crosslinking of the shell, of the core or at the interface between hydrophobic/ hydrophilic zones. ${ }^{12,13}$ Even if the subject has been studied for over 15 years, new cases are still being published, with different 
crosslinking methods, such as radical reactions, ${ }^{14-17}$ reversible disulfide bonds, ${ }^{18-24}$ or coupling reactions. ${ }^{25-36}$ Original approaches have used uracyl moieties ${ }^{37}$ dopamine oxidation in the presence of air $^{38}$ or cinnamate reversible dimerization. ${ }^{39}$ More sophisticated systems present a crosslinking enabling the release of the drug with adequate physiological conditions (presence of dithiothreitol or glutathione, difference of $\mathrm{pH}) .^{18,21-25,27,34,35,40-42}$ Interestingly, Rajdev showed that $\mathrm{H}^{-}$ bonding between hydroxyl groups in poly(hydroxyethyl methacrylate) could be used as supramolecular crosslinking. ${ }^{43}$ The same concept could be suggested for micelles exhibiting a large amount of $\pi-\pi$ stacking. ${ }^{44}$

Regarding the therapeutic efficiency, crosslinked systems are most often tested in vitro on $2 \mathrm{D}$ cell culture. This almost always leads to a lower activity of the drug compared to the free one or to its form encapsulated in an uncrosslinked vector. ${ }^{16,17,19,25,34,38,45}$ Only in a few cases are activities on the same range or even better. ${ }^{20,26,31,35,41}$ In a general manner, in vivo studies remain seldom, although moving away from $2 \mathrm{D}$ cell culture is increasingly shown to be essential for a better development of future therapeutics. ${ }^{46}$ However, if in vivo characterizations of the therapeutic efficiency are a mandatory step toward application, they have two main drawbacks, the first one being the ethical issue of sacrificing numerous animals and the second one the price. An alternative is the use of 3D cell culture models, such as spheroids. ${ }^{4-50} 3 \mathrm{D}$ cell culture models are more relevant to in vivo cell organization since extracellular matrix as well as homo- or hetero-cell-cell contacts are present. Another advantage of spheroids is that they limit the use of animals, in agreement with the $3 \mathrm{R}$ (replacement, reduction and refinement) rule on animal experimentation. In all the different studies on drug delivery from crosslinked self-assemblies, to our knowledge, only one, published during the writing of this paper, assessed the therapeutic efficiency of doxorubicin or paclitaxel encapsulated in polymeric micelles using spheroids. ${ }^{33,51}$ The observed trend was that, contrary to the usual one observed in $2 \mathrm{D}$ cultures, crosslinking of the vector may lead to an improved penetration of the encapsulated drug in the spheroid.

Based on this literature analysis, the aim of our work was twofold: first to characterize and compare the efficiency of crosslinked nanovectors, and secondly to examine their photocytotoxicity both on 2D and 3D cell cultures in the field of photodynamic therapy (PDT). The systems we chose are based on poly(ethyleneoxide- $b$ - $\varepsilon$-caprolactone) and the encapsulated molecule is Pheophorbide a (Pheo), a photosensitizer classically used for PDT. Indeed, the progress in irradiation systems has promoted this therapeutic approach. ${ }^{52,53}$ However, regular PDT uses the injection of free photosensitizers which are often hydrophobic and/or subject to aggregation, leading to a lower efficiency. Furthermore, the biodistribution observed is rarely in favor of the targeted tumor, provoking a sensibility to light for the patient. We have recently shown that polymeric micelles were good candidates as vectors to encapsulate Pheo in its monomeric form and that this led to a strong increase in photocytotoxicity. ${ }^{54}$
This manuscript therefore describes the formation of different crosslinked self-assemblies, their characterization, before examining the PDT efficiency both in 2D and 3D tumor cell cultures.

\section{Materials and methods}

\section{Chemicals}

The poly(ethyleneoxide- $b$ - $\varepsilon$-caprolactone) polymers (PEO-PCL, Scheme 1) were purchased from Polymer Source Inc. (Dorval Montréal, Canada), Pheo from Wako (Osaka, Japan). Three polymers were used, having different molar masses, which are mentioned in their naming: PEO-PCL 2000-2800, PEO-PCL 5000-4000 and PEO-PCL 2000-7000. PrestoBlue and cell culture medium were purchased from Invitrogen Life Technologies (Saint Aubin, France). Penicillin, streptomicyn, fetal bovine serum, PBS, and acryloyl chloride were from SigmaAldrich (Saint Quentin Fallavier, France). Celltiter-Glo 3D cell viability assay was purchased from Promega (Madison, WI, USA).

\section{Polymer acrylate functionalization}

In a dry clean flask, $500 \mathrm{mg}$ of dried polymer were dissolved in 8 $\mathrm{mL}$ of anhydrous dichloromethane (dried over alumina). 100 equivalents of acryloyl chloride and 10 equivalents of triethylamine in $7 \mathrm{~mL}$ of anhydrous dichloromethane were slowly added at $0{ }^{\circ} \mathrm{C}$ under argon atmosphere. The reaction was further stirred in the ice during $4 \mathrm{~h}$ and at room temperature for $48 \mathrm{~h}$. Purification was performed by a cryo-distillation after the addition of $3 \mathrm{~mL}$ of ethyl acetate. The solution was then centrifuged in a Hettich universal $32 \mathrm{R}$ at $10{ }^{\circ} \mathrm{C}(4000 \mathrm{rpm}$ during $10 \mathrm{~min}$ ). The supernatant was recovered and the solvent evaporated to obtain the polymer. The polymer was then dissolved in $1 \mathrm{~mL}$ of dichloromethane and put in $20 \mathrm{~mL}$ of absolute ethanol. Dichloromethane was removed at $30{ }^{\circ} \mathrm{C}, 150 \mathrm{mbar}$

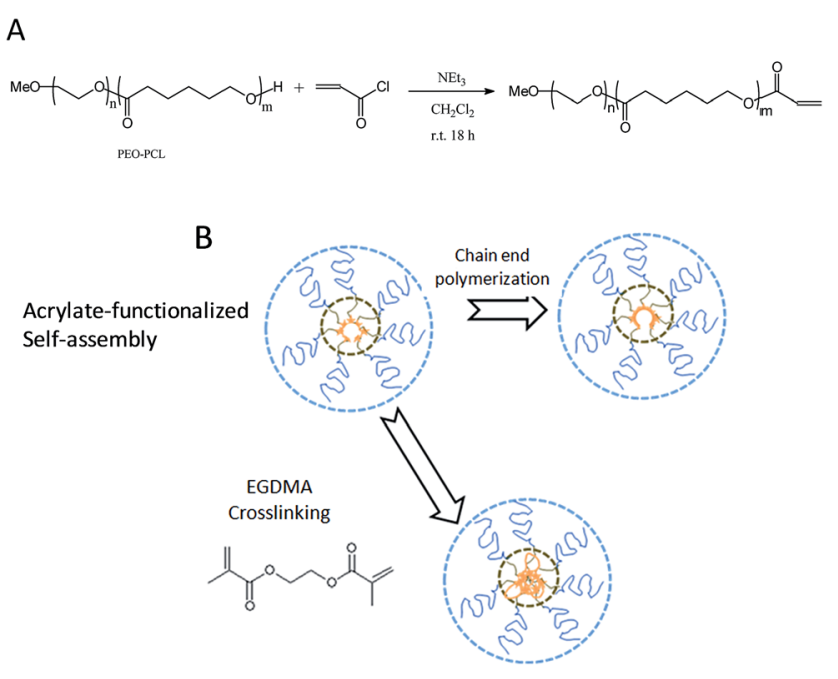

Scheme 1 Formation of crosslinked systems. (A) Acrylate functionalization of the polymers; (B) processes used for self-assembly consolidation. 
during $30 \mathrm{~min}$ and the solution was put at $-20{ }^{\circ} \mathrm{C}$ during $48 \mathrm{~h}$. After centrifugation at $-10{ }^{\circ} \mathrm{C}(8000 \mathrm{rpm}$ during $10 \mathrm{~min})$, the pellet was taken out and dried. Different functionalization ratios were achieved depending of the polymer (see discussion) and an average $64 \pm 7 \%$ yield of recovered polymer was reached. ${ }^{1} \mathrm{H}$ NMR $\left(\mathrm{CDCl}_{3}, 300 \mathrm{MHz}, 128\right.$ cycles with $10 \mathrm{~s}$ relaxation time, ppm): 6.33 (acrylate, dd); 6.12 (acrylate, dd); 5.83 (acrylate, dd); 4.02 (- $\left.\mathrm{CH}_{2}-\mathrm{OCO}, \mathrm{PCL}\right) ; 3.61$ (- $\left.\mathrm{CH}_{2}-\mathrm{O}-, \mathrm{PEO}\right) ; 3.34$ (MeO, s); 2.27 $\left(-\mathrm{CH}_{2}-\mathrm{CO}-, \mathrm{PCL}\right) ; 1.61\left(-\mathrm{CH}_{2}-, \mathrm{PCL}\right) ; 1.37\left(-\mathrm{CH}_{2}-, \mathrm{PCL}\right)$.

\section{Preparation of polymer micelles (PEO-PCL 2000-2800 and PEO-PCL 5000-4000)}

$0.4 \mathrm{~mL}$ of an acetone polymer solution $\left(50 \mathrm{mg} \mathrm{mL}^{-1}\right)$ was added dropwise into $5 \mathrm{~mL}$ of milliQ water (resistivity $18 \mathrm{M} \Omega \mathrm{cm}$, filtered on a $0.2 \mu \mathrm{m}$ filter) as previously described (final concentration $\left.4 \mathrm{mg} \mathrm{mL}{ }^{-1}\right) .{ }^{54-56}$ The solution was left standing for two days for removing acetone.

\section{Preparation of polymer worm-like self-assemblies (PEO-PCL 2000-7000)}

A $20 \mathrm{mg} \mathrm{mL} \mathrm{m}^{-1}$ polymer solution in chloroform was prepared and the solvent was evaporated on a rotary evaporator to form a regular film which was further dried under vacuum for 4 hours. This was then rehydrated with $2 \mathrm{~mL}$ of milliQ water (resistivity $18 \mathrm{M} \Omega \mathrm{cm}$, filtered on a $0.2 \mu \mathrm{m}$ filter), heated at $65^{\circ} \mathrm{C}$ for $30 \mathrm{~min}$ and $1 \mathrm{~h}$ at $65{ }^{\circ} \mathrm{C}$ under sonication. The solution was then extruded on a mini-extruding system from Polar Avanti Lipids with a polycarbonate membrane with a cutoff at $0.4 \mu \mathrm{m}$.

\section{Crosslinking of all self-assemblies}

This was made either with 0.3 mol\% sodium persulfate $\left(\mathrm{Na}_{2} \mathrm{~S}_{2} \mathrm{O}_{8}\right.$, in water), sodium persulfate and sodium thiosulfate $\left(\mathrm{Na}_{2} \mathrm{~S}_{2} \mathrm{O}_{3}\right.$, in water), azobis(isobutyronitrile) (AIBN, solution in acetone), or no initiator other than light. The ratio between the initiators and the acrylate functions was kept at $3 \mathrm{~mol} \%$. For chain-end polymerized systems, the initiator solution was added to the micelle one $\left(4 \mathrm{mg} \mathrm{mL}^{-1}\right)$ and degassed under argon. This was put at $50{ }^{\circ} \mathrm{C}$ during 24 to $72 \mathrm{~h}$. For crosslinking, the solution additionally contained $15 \mu \mathrm{L}$ of ethyleneglycoldimethacrylate (EGDMA) ( $1 \mathrm{~mol} \%$ in acetone). During the reaction course, a second portion of $15 \mu \mathrm{L}$ of EGDMA was added after $24 \mathrm{~h}$. The entire crosslinking tests have been carried out in triplicate. Crosslinking percentage was obtained by ${ }^{1} \mathrm{H}$ NMR after freeze-drying to remove water and re-suspension in $\mathrm{CDCl}_{3}$.

\section{Loading of the micelles with Pheo}

For uncrosslinked micelles, Pheo was added to the acetone solution during the preparation of the self-assemblies. For all crosslinked self-assemblies and uncrosslinked PEO-PCL 20007000 worm-like assemblies, a $0.5 \mathrm{mg} \mathrm{mL}^{-1}$ Pheo solution in acetone was used and the adequate volume $(80-160 \mu \mathrm{L}$ depending on the system) added to the aqueous solution ( 2 or 5 $\mathrm{mL}$ depending on the system) of crosslinked micelles. The solution was left standing for two days for removing acetone.
The chosen ratio of Pheo/polymer $1 / 30 \mathrm{~mol} / \mathrm{mol}$ enabled us to obtain a full Pheo encapsulation, as shown in our earlier studies and in ESI (Fig. S8†). ${ }^{57}$

\section{Dialyses experiments}

Solutions of loaded Pheo/self-assemblies were diluted in order to obtain a Pheo concentration at $10^{-6}$ M. $2 \mathrm{~mL}$ of these diluted solutions were introduced in a dialysis kit (GE Healthcare BioSciences, membrane with MWCO at $8 \mathrm{kDa}$ ) and dialyzed versus $800 \mathrm{~mL}$ of water at $37^{\circ} \mathrm{C}$. The release of Pheo was followed up by measuring the optical density of the internal solution at 688 (Pheo alone) and $669 \mathrm{~nm}$ (Pheo in selfassemblies).

\section{Dynamic light scattering (DLS)}

DLS was carried out at $25{ }^{\circ} \mathrm{C}$ on a Malvern (Orsay, France) Zetasizer NanoZS. Solutions were analyzed in triplicate without being filtered in order to characterize the plain samples. Data were analyzed by the general-purpose non-negative least squares (NNLS) method to obtain the intensity-weighted distribution of diffusion coefficients $(D)$ of the solutes. The typical accuracy for these measurements was $10-20 \%$ for systems exhibiting a polydispersity index lower than 0.4 . This intensity-weighted distribution can be converted, using Mie theory, to a number-weighted distribution describing the relative proportion of multiple components in the sample based on their number rather than based on their scattering. The intensity distribution is naturally weighted according to the scattering intensity of each particle fraction or family. As such, the intensity distribution can be somewhat misleading, since a small amount of aggregation or presence or a larger particle species can dominate the distribution. Malvern software considers the Mie scattering theory for spherical filled objects.

\section{Transmission Electron Microscopy (TEM)}

TEM analyses were performed with a Hitachi HT7700 (Hitachi High Tech, Hitachinaka, Japan) microscope (accelerating voltage of $75 \mathrm{kV}$ ). Small amounts of particle suspensions in water were deposited onto a discharged copper grid coated with a carbon membrane, left for 1-3 min depending on the solution, and gently dried with absorbing paper. A drop of uranyl acetate solution was deposited onto the grid for 10 seconds, and the grid was then dried under a lamp for at least $5 \mathrm{~min}$. When the images contained a large number of distinct objects (typically >200), a measurement of the mean size (as well as the standard deviation) was performed with Image $\mathrm{J}$ software (http://imagej.nih.gov/ij/).

\section{Asymmetrical Flow Field-Flow Fractionation (AsFlFFF)}

The AsFlFFF instrument was an Eclipse 3 System (Wyatt Technology Europe, Dernbach, Germany). The AsFlFFF channel had a trapezoidal geometry with a length of $17.3 \mathrm{~cm}$, an initial breadth of $1.1 \mathrm{~cm}$, and a final breadth of $0.27 \mathrm{~cm}$. A $250 \mu \mathrm{m}$ thick Mylar spacer was placed between the ultrafiltration membrane and the upper glass plate. The accumulation wall 
was an ultrafiltration membrane of regenerated cellulose with a 10 kDa cut-off (Wyatt Technology Europe, Dernbach, Germany). An Agilent 1100 Series Isocratic Pump (Agilent Technologies, Waldbronn, Germany) with an in-line vacuum degasser and an Agilent 1100 Autosampler delivered the carrier flow and handled sample injection into the AsFlFFF channel. Water with $0.02 \%$ sodium azide filtered before use (vacuum filtration system using Gelman filters of $0.1 \mathrm{~mm}$ ) was used as eluent. A $0.1 \mu \mathrm{m}$ in-line filter (VVLP, Millipore, Germany) was installed between the pump and the AsFlFFF channel. The products were detected with 18 angles Multi-Angle Light Scattering (MALS) DAWN Heleos II (Wyatt Technology, Santa Barbara, CA, US) equipped with a QELS (DLS) at $99^{\circ}$, an OptilaRex Refractometer (Wyatt Technology, Santa Barbara, CA, US), and a UV detector Agilent $1100(\lambda=412 \mathrm{~nm})$. The MALS detectors were normalized with bovine serum albumin (BSA). Calibration of scattering intensity was performed with HPLC-grade filtered toluene. Water, which was filtered with $0.02 \%$ sodium azide before use, (vacuum filtration system using Gelman filters of 0.1 $\mu \mathrm{m})$ was used as an eluent. For separation, the channel flow rate $V_{\text {out }}$ was fixed at $0.3 \mathrm{~mL} \mathrm{~min}^{-1}$. In focus mode, the flow rate was stabilized $1 \mathrm{~min}$ before injection at $1.5 \mathrm{~mL} \mathrm{~min}{ }^{-1}$. Twenty microliters of the sample solution were injected into the AsFlFFF channel at a flow rate of $0.2 \mathrm{~mL} \mathrm{~min}^{-1}$ for $6 \mathrm{~min}$. After injection, one minute of focus was maintained before the elution started.

In elution mode, the cross-flow rate was fixed at $0.4 \mathrm{~mL}$ $\min ^{-1}$ for $20 \mathrm{~min}$. Cross flow was then stopped in order to eliminate all particles present in the AsFlFFF system.

For characterization of PEO-PCL 2000-7000 systems, the following modification was used. In elution mode, the crossflow rate decreased from $0.4 \mathrm{~mL} \mathrm{~min}^{-1}$ to $0.1 \mathrm{~mL} \mathrm{~min}^{-1}$ in 10 min, and subsequently fixed at $0.1 \mathrm{~mL} \mathrm{~min}^{-1}$ for $30 \mathrm{~min}$. Cross flow was then stopped in order to eliminate all particles present in the AsFlFFF system.

\section{Cell culture}

The HCT-116 cell line (ATCC \#CCL-247) originated from a human colorectal carcinoma, the FaDu cell line (ATCC \#HTB43) from a human squamous cell carcinoma. Both HCT-116 and FaDu cells were grown in Dulbecco's Modified Eagles Medium (Invitrogen) containing $4.5 \mathrm{~g} \mathrm{~L}^{-1}$ glucose, GlutaMAX and pyruvate, supplemented with $10 \%(\mathrm{v} / \mathrm{v})$ heat inactivated fetal bovine serum (FBS), $100 \mathrm{U} \mathrm{mL}^{-1}$ penicillin and $100 \mu \mathrm{g} \mathrm{mL}^{-1}$ streptomycin. Cells were maintained at $37{ }^{\circ} \mathrm{C}$ in a humidified atmosphere containing $5 \% \mathrm{CO}_{2}$.

\section{Cytotoxicity and photocytotoxicity of Pheo-loaded polymeric micelles}

They were performed on 2D adherent cells monolayers. HCT116 and FaDu cells were seeded into 96-well plates (4000 cells per well). Cytotoxicity of polymer self-assemblies $(1 \mu \mathrm{M}, 10 \mu \mathrm{M}$, $100 \mu \mathrm{M})$ loaded with Pheo $(1 / 30 \mathrm{~mol} / \mathrm{mol})$ was assessed after 48 $\mathrm{h}$ incubation time. Phototoxicity of Pheo-loaded self-assemblies $(1 / 30 \mathrm{~mol} / \mathrm{mol})$ was assessed after $48 \mathrm{~h}$ incubation at $37^{\circ} \mathrm{C}$ after a set of three photoactivations, ${ }^{54}$ which were performed with an overhead projector with a band-pass filter $(\lambda>400 \mathrm{~nm})$, representing a total dose of $8.2 \mathrm{~J} \mathrm{~cm}^{-2}$. Concentrations used for Pheo alone were $0.033 \mu \mathrm{M}, 0.33 \mu \mathrm{M}$ and $3.3 \mu \mathrm{M}$, corresponding to the same concentrations in the experiments with the loaded polymer self-assemblies. Viability was assessed with PrestoBlue reagent (Invitrogen) according to the manufacturer instructions. For every set of experiments, six biological replicates were produced and analyzed. Statistical differences between values were assessed by Dunnett's multiple comparison tests which compare each condition with their respective control. All data were expressed as mean \pm standard error of the mean (SEM), and overall statistical significance was set at $p<0.05$.

\section{Generation of 3D tumor spheroids}

HCT-116 and FaDu spheroids were produced by the nonadherent technique as previously described. ${ }^{54}$ Briefly, 10000 FaDu cells or 1000 HCT-116 cells were seeded in $300 \mu \mathrm{L}$ of medium in each well of ultra-low attachment 96-well plates from Corning (Fisher Scientific, Illkirch, France). Spheroids were cultivated for 5 days before incubation with the nanovectors (or free Pheo or Pheo-loaded self-assemblies) at $37^{\circ} \mathrm{C}$ in a humidified atmosphere containing $5 \% \mathrm{CO}_{2}$.

\section{Pheophorbide penetration in 3D spheroid models}

For the localization of pheophorbide a in the 3D culture model, fresh 5 day old FaDu or HCT-116 spheroids were incubated with encapsulated $3 \mu \mathrm{M}$ encapsulated Pheo for $30 \mathrm{~min}$ at $37^{\circ} \mathrm{C}$ and observed by two-photon microscopy on 7MP FLIM microscope (Zeiss, Le Pecq, France). The images were stacked using Image J software (NIH, Bethesda, MD, USA).

\section{Photodynamic therapy of 3D tumor spheroids}

HCT-116 and FaDu spheroids were incubated with free or encapsulated Pheo $30 \mathrm{~min}([\mathrm{Pheo}]=3 \mu \mathrm{M}$, [Pheo $] /[$ polymer $]=$ $1 / 30 \mathrm{~mol} / \mathrm{mol}$ ) before the first photoactivation. Spheroids were irradiated for $8 \mathrm{~min}$ using an overhead projector lamp with a band-pass filter $(\lambda>400 \mathrm{~nm})$. The total energy received was 8.2 $\mathrm{J} \mathrm{cm}^{-2}$ (i.e., $8 \mathrm{~min}$ of irradiation $=8.2 \mathrm{~J} \mathrm{~cm}^{-2}$ ). Then, $8 \mathrm{~min}$ illumination took place each $24 \mathrm{~h}$, over a two-day period. Spheroids treated by PDT were observed by optical microscopy (Olympus BX53 equipped with a $\times 5 \mathrm{M}$ plane $\mathrm{N}$ objective in phase contrast) $6 \mathrm{~h}$ after the last photoactivation, i.e. after $78 \mathrm{~h}$ of incubation with polymeric micelles and during at least 3 more days.

\section{Surface analysis and reliability}

Spheroids treated by PDT were observed by optical microscopy (Olympus BX53 equipped with a $\times 5 \mathrm{M}$ plane $\mathrm{N}$ objective in phase contrast). The PDT efficiency was evaluated by measuring the surface of the living spheroids, which was extracted from the image with image J software and evolution over the time was compared. The experiments were made in hexaplicate. All data were expressed as mean \pm SEM.

The viability of some samples was tested with the ATP Invitrogen assay kit in order to validate the microscopy 
methodology. The comparison was made between the ATP concentration of the treated spheroid divided by the ATP concentration of the control one of the same cell line, and the volume ratio of the treated spheroid divided by his control. We assumed that the spheroids were spherically shaped as shown in the different images and that the ATP is directly linked to the number of living cells. We also assumed that this number was linked to the spheroid volume, this assumption was only possible because we use small spheroid without any dead core.

The reliability was scored excellent for the HCT-116 cells (Pearson coefficient $r^{2}=0.9807 ; N=32$ ) and for FaDu (Pearson coefficient $r^{2}=0.9788 ; N=32$ ).

The coding of the image was also tested: the same batch of images was analyzed twice two months apart with the same program and in the same way. As for the ATP control, a Pearson test was used to assess the reliability which was scored excellent for both cell lines HCT-116 (Pearson coefficient $r^{2}=0.9987 ; N=$ 80 ) and FaDu (Pearson coefficient $\left.r^{2}=0.9928 ; N=120\right)$.

\section{Results}

\section{Crosslinked polymer self-assemblies synthesis and characterization}

Three different poly(ethyleneoxide- $b$ - $\varepsilon$-caprolactone) polymers (PEO-PCL) were chosen, namely PEO-PCL 2000-2800, PEO-PCL 5000-4000 and PEO-PCL 2000-7000, owing to our earlier studies. ${ }^{54,56,57}$ We have already shown that the first two polymers led to polymeric micelles with a close size range, whereas the last one led to elongated self-assemblies. In addition to study crosslinking effect on the PDT efficiency, these choices enabled us first to examine the molecular weight effect of the polymer without changing the self-assembly morphology (PEO-PCL 2000-2800 vs. 5000-4000) and secondly to examine elongated systems which were suggested in the literature as more efficient than spherical ones. ${ }^{58-60}$

These polymers were functionalized by grafting an acrylate group, through reaction between hydroxyl end groups and acryloyl chloride, at the end of different poly(ethyleneoxide- $b$ $\varepsilon$-caprolactone) copolymers (Scheme 1A) following already published procedures. ${ }^{\mathbf{1 4 , 6 1 - 6 3}}$ Functionalization ratio was determined by ${ }^{1} \mathrm{H}$ NMR (Fig. S1 $\dagger$ ) from the ratio between acrylate functions to $\mathrm{MeO}$ or caprolactone units and was $90 \%$ for $\mathrm{PEO}-$ PCL 2000-2800 and PEO-PCL 2000-7000. For PEO-PCL 50004000 , it was $60 \%$. These yields are consistent with those obtained in the literature. Depending on the conditions used, this reaction has been observed to have yields as low as $20 \%$ in some cases. ${ }^{64}$ Over the whole paper, all control polymers correspond to acrylate functionalized molecules, even if this if not systematically mentioned for conciseness.

The self-assemblies were formed by nanoprecipitation for PEO-PCL 2000-2800 and PEO-PCL 5000-4000, and film rehydration/extrusion for PEO-PCL 2000-7000, according to already published procedures. ${ }^{56,57}$

Several initiating agents were then examined to induce acrylate polymerization on PEO-PCL 2000-2800, with multiple reaction protocols (Table 1). ${ }^{\mathbf{6 1 - 6 3 , 6 5}}$ This showed that the simplest method heating at $50{ }^{\circ} \mathrm{C}$ without addition of any agent led to the
Table 1 Typical acrylate conversions of PEO-PCL 2000-2800 for $24 \mathrm{~h}$ with different initiating agents

\begin{tabular}{ll}
\hline Initiating agent & ${ }^{1} \mathrm{H}$ NMR calculated yield \\
\hline $\mathrm{Na}_{2} \mathrm{~S}_{2} \mathrm{O}_{8}\left(50{ }^{\circ} \mathrm{C}\right)$ & $27 \%$ \\
$\mathrm{Na}_{2} \mathrm{~S}_{2} \mathrm{O}_{8} / \mathrm{Na}_{2} \mathrm{~S}_{2} \mathrm{O}_{3}$ (room temperature) & $14 \%$ \\
$\mathrm{AIBN}\left(50{ }^{\circ} \mathrm{C}\right)$ & $23 \%$ \\
Heated $\left(50{ }^{\circ} \mathrm{C}\right)$ & $37 \%$
\end{tabular}

best conversion of acrylates. In such a case, light is expected to provide the adequate initiating radicals.

The protocol of simple heating at $50{ }^{\circ} \mathrm{C}$ was thus chosen to induce the acrylate reaction for all self-assemblies. Two possible methods were tested for consolidating the self-assemblies (Scheme 1B). Reacting the acrylate functions alone leads to the formation of assemblies of comb polymers whereas simultaneous addition of EGDMA should lead to crosslinked systems. As shown in Table 2, the best conversion was obtained in the presence of EGDMA added in two sequences, leading to conversions between 60 and 75\% (example of ${ }^{1} \mathrm{H}$ NMR is given in Fig. S2 $\dagger$ ). EGDMA having a $\log P$ partition coefficient around 2.4 , it can be expected to be mainly present in the selfassemblies and only as traces in the water phase. Inside the self-assemblies, it could locate either in the PEO shell or in the PCL core. Whatever its starting location may be, the fact that in its presence the acrylate conversion increased showed that at least some of the EGDMA molecules got in the core to react with the acrylate functions. It is noteworthy that for PEO-PCL 20007000 a partial conversion of acrylate was already present during the preparation of the self-assembly, owing to the process involving heating at $65{ }^{\circ} \mathrm{C}$ during a couple of hours.

The reacted self-assemblies were then characterized by Dynamic Light Scattering (DLS) and Transmission Electron Microscopy (TEM). Results are presented in Table 3, Fig. 1 and $\mathrm{S} 3 . \dagger$ Compared to non-functionalized self-assemblies, ${ }^{56,57}$ the introduction of acrylate functions changed neither the morphology nor the size for PEO-PCL 2000-2800 and PEO-PCL 5000-4000 leading to micelles of $c a .15 \mathrm{~nm}$ diameter. In the case of PEO-PCL 2000-7000, the analysis of size either by DLS or TEM should be taken with caution and is given here only as indication, since the self-assemblies are elongated systems.

Chain-end polymerization of acrylates or crosslinking with EGDMA did not lead to a modification of the morphology and

Table 2 Acrylate conversions obtained from ${ }^{1} \mathrm{H}$ NMR

\begin{tabular}{|c|c|c|c|}
\hline Acrylate conversion \% & $\begin{array}{l}\text { PEO-PCL } \\
2000-7000\end{array}$ & $\begin{array}{l}\text { PEO-PCL } \\
5000-4000\end{array}$ & $\begin{array}{l}\text { PEO-PCL } \\
2000-2800\end{array}$ \\
\hline Acrylate functionalization ${ }^{a}$ & $90 \%$ & $60 \%$ & $90 \%$ \\
\hline $\begin{array}{l}\text { After object assembly } \\
\text { before crosslinking }\end{array}$ & $20 \%$ & $0 \%$ & $0 \%$ \\
\hline Without EGDMA & $60 \%$ & $40 \%$ & $40 \%$ \\
\hline $15 \mu \mathrm{L}$ EGDMA & $60 \%$ & $30 \%$ & $60 \%$ \\
\hline $15 \mu \mathrm{L}+15 \mu \mathrm{L}$ EGDMA & $75 \%$ & $60 \%$ & $70 \%$ \\
\hline
\end{tabular}

${ }^{a}$ Acrylate functionalization of the polymer before reaction. 
Table 3 DLS and TEM characterization of self-assemblies

\begin{tabular}{|c|c|c|c|c|c|}
\hline Polymer & Self-assembly & $\begin{array}{l}\text { DLS size int. } \\
(\mathrm{nm})\end{array}$ & $\begin{array}{l}\text { DLS size number } \\
(\mathrm{nm})\end{array}$ & $\mathrm{PDI}^{a}$ & $\begin{array}{l}\text { Mean size from TEM } \\
(\mathrm{nm})\end{array}$ \\
\hline \multirow[t]{2}{*}{ PEO-PCL 2000-2800 } & Acrylate functionalized & 12 & 9 & 0.28 & $10 \pm 4$ \\
\hline & Crosslinked/EGDMA & 13 & 9 & 0.49 & $16 \pm 4$ \\
\hline \multirow[t]{2}{*}{ PEO-PCL 5000-4000 } & Acrylate functionalized & 25 & 17 & 0.36 & $18 \pm 5$ \\
\hline & Chain-end polymerization & 24 & 19 & 0.22 & n.d. \\
\hline & Chain-end polymerization & 165 & 40 & 0.41 & n.d. \\
\hline & Crosslinked/EGDMA & 400 & 105 & 0.41 & 30-800 long, 25 wide \\
\hline
\end{tabular}

${ }^{a}$ Polydispersity index.

only a small evolution of the size. TEM (Fig. 1 and $\mathrm{S} 4 \dagger$ ) showed the presence of self-assemblies, the size of which was reasonably close from the starting objects for PEO-PCL 2000-2800 micelles.

For PEO-PCL 2000-7000, the crosslinking step induced an increase in size. Step by step analysis of the solutions, although no
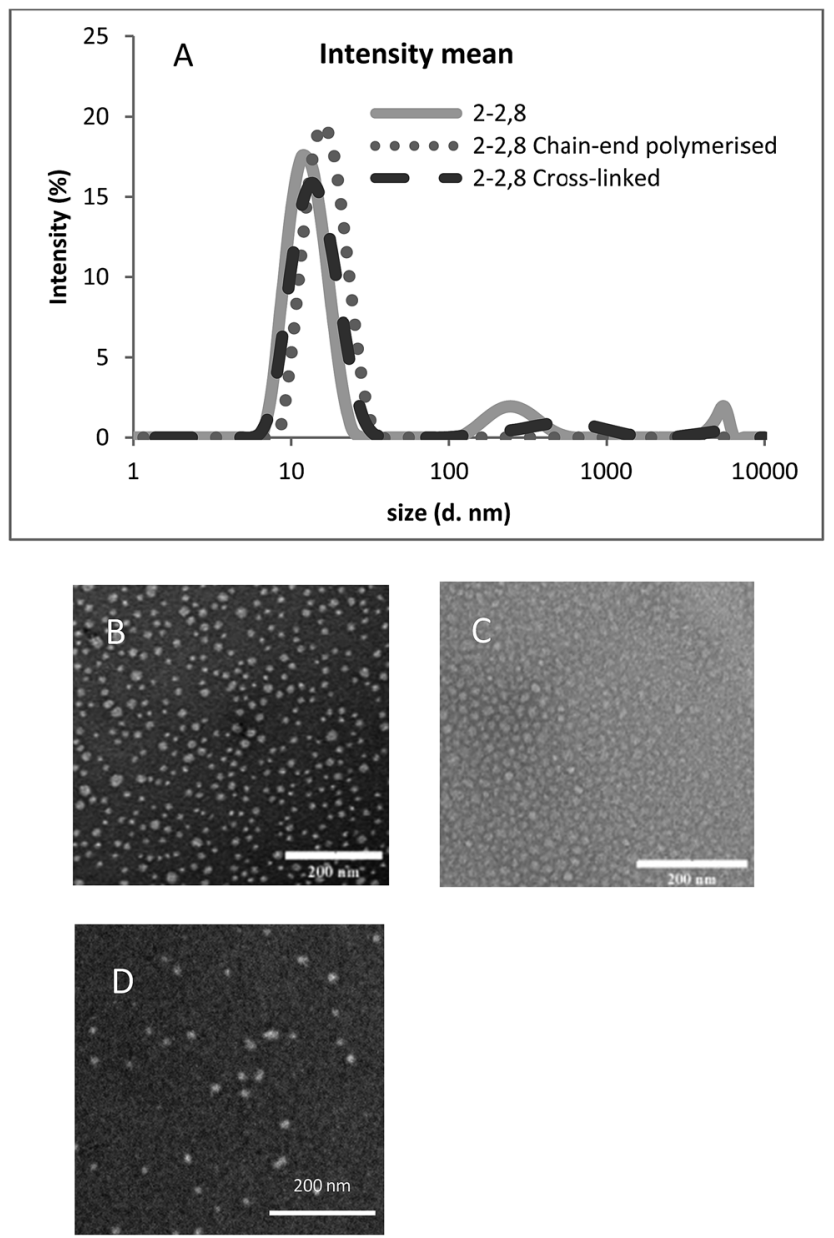

Fig. 1 Typical DLS (A) and TEM characterization of PEO-PCL 20002800 self-assemblies analyses. 2-2,8 represents PEO-PCL 20002800. For TEM, the scale bar represents $200 \mathrm{~nm}$. (B) Empty micelles; (C) chain-end polymerized micelles; (D) crosslinked micelles. statistical analysis could be performed satisfyingly, showed that this increase in size mainly occurred during the prolonged heating for crosslinking, and not during the swelling and sonication processes (Fig. S5 $\dagger$ ). Therefore, this increase in size could be attributed to the fact that such self-assemblies are kinetically frozen and can lead to re-arrangement upon heating over a long time.

As already described in a previous work, ${ }^{56}$ in order to have a full insight of the composition of self-assemblies solutions, DLS or TEM should be used together with another technique which is able to discriminate possible different populations. Such a technique can be Asymmetrical Flow Field-Flow Fractionation (AsFlFFF). We have for instance shown that only AsFlFFF was able to enlighten the real ratio between two populations of nanovectors based on PEO-PCL 5000-1400. ${ }^{57}$ Thus, reacted selfassemblies were further characterized by AsFlFFF (Fig. 2).

The first peak observed on some fractograms at ca.11 minutes is an artifact specific of the AsFlFFF technique. The self-assemblies all appear as a unique peak in the fractograms, proving the presence of only one type of self-assembly for each system. Furthermore, only a small shift in the elution time was observed for all the reacted polymeric self-assemblies, showing that the chemical process did not modify the objects fundamentally. This is essential for the purpose of this study. In identical analytical conditions, peaks' retention times for PEOPCL 5000-4000 assemblies are slightly higher than those obtained for PEO-PCL 2000-2800 assemblies. This indicates that PEO-PCL 5000-4000 assemblies are larger than PEO-PCL 20002800 ones, in agreement with DLS data (Table 3).

For all self-assemblies, Pheo loading was then performed only after acrylate polymerization by adding a small volume of acetone solution of Pheo followed by evaporation of the solvent. DLS and TEM further confirmed that the objects were unaffected (Fig. 1, S6 and S7†), either in their size or shape. This was expected considering that the volume of acetone was small compared to that of water. Furthermore, based on our previous studies, ${ }^{57}$ the ratio between the polymer and Pheo $(30 / 1 \mathrm{~mol} /$ mol) ensured a full Pheo encapsulation. This was checked by absorbance spectra, since free Pheo exhibits a band at $690 \mathrm{~nm}$, which is shifted to $665-670 \mathrm{~nm}$ in hydrophobic environments in its disaggregated form (Fig. S8†). 

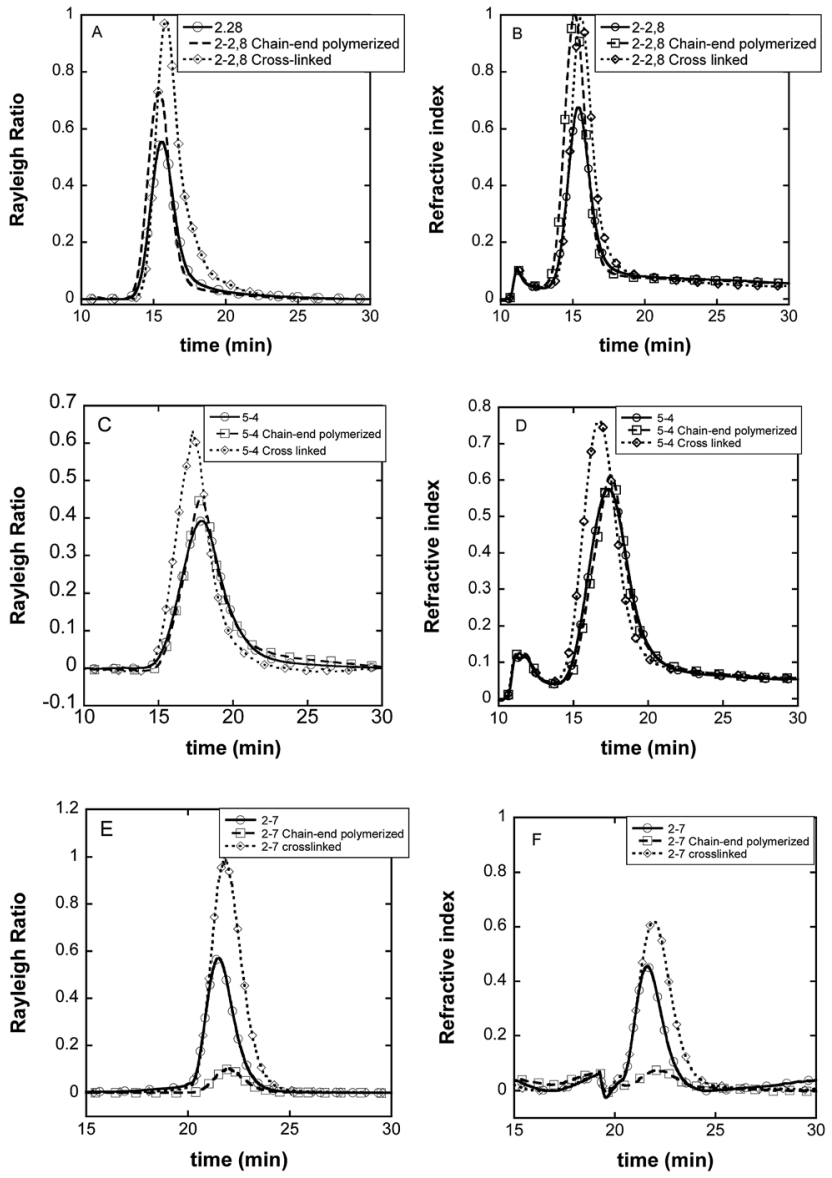

Fig. 2 AsFIFFF analyses of empty reacted self-assemblies. (A and B) PEO-PCL 2000-2800; (C and D) PEO-PCL 5000-4000; ( $E$ and F) PEO$P C L$ 2000-7000. On the inserts, 2-2,8, 5-4 and 2-7 respectively represent PEO-PCL 2000-2800, PEO-PCL 5000-4000 and PEO-PCL 2000-7000. (A, C and E) Fractograms are MALLS signals. ( $B, D$ and $F$ ) are RI signals.

\section{Self-assembly stability, photosensitizer release characterizations}

The stability was first examined by DLS follow-up at $25{ }^{\circ} \mathrm{C}$. Whereas uncrosslinked micelles of PEO-PCL 2000-2800 and PEO-PCL 5000-4000 were observed to be stable only over a two week period, the crosslinked systems did not change for a period longer than three months, representing a 7 -fold improvement of the stability (Fig. 3 and S9†). The same stability was observed for chain-end polymerized systems. For PEO-PCL 2000-7000, both uncrosslinked and crosslinked self-assemblies were observed to be stable over a 2 month period (data not shown).

Typical studies in the literature evaluated the crosslinking of the nanovectors by a redissolution test in organic solvent ${ }^{15,19,20,25-28,36,38,45}$ or high dilution..$^{15,19,21,23,28,34,42,61,66}$ Whereas uncrosslinked systems will disassemble, crosslinked ones should resist these treatments. The same principle is used with temperature for polymers presenting a Lower Critical Solution Temperature (LCST); only the crosslinked micelles will resist below LCST. ${ }^{41}$ Exposure to surfactants, ${ }^{22,63,64}$ salts $^{21,23,29,66}$

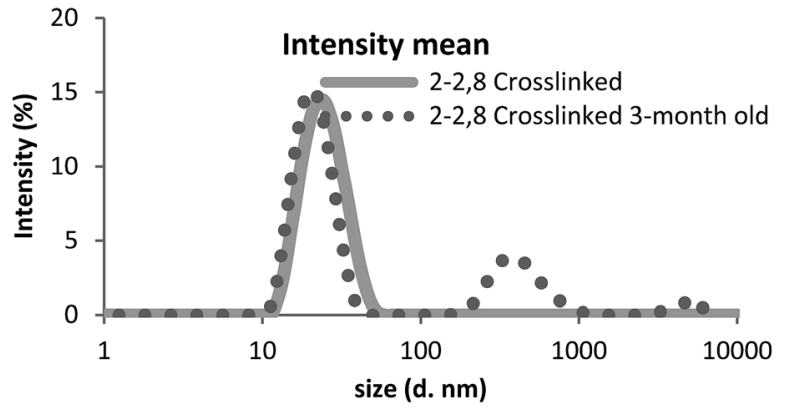

Fig. 3 DLS characterization of stability over time. 2-2,8 represents PEO-PCL 2000-2800. - Crosslinked PEO-PCL 2000-2800 just after the synthesis, $\cdots$ the same after 3 months.

or proteins ${ }^{22,61}$ has also been used to assess the stability of the crosslinked micelles.

In our case, the different self-assemblies were thus exposed to an increasing quantity of tetrahydrofuran (THF), which is a good solvent for both PEO and PCL blocks. The results are presented in Fig. 4 for PEO-PCL 2000-2800 and 5000-4000 systems. All correlograms (either of unreacted or reacted systems) exhibited several populations for THF ratios higher than $40 \% \mathrm{v} / \mathrm{v}$, rendering their analysis unsuitable (Fig. S10 $\dagger$ ). The corresponding data should therefore be taken with extreme caution and considered only as indicative. For PEOPCL 2000-2800, a clear difference is observed between the unreacted and the crosslinked systems. The size for the crosslinked one remained stable up to $40 \% \mathrm{THF}$, whereas the unreacted one gradually increased. For PEO-PCL 5000-4000, both unreacted and crosslinked self-assemblies were stable for THF content up to $50 \%$, after which both systems were
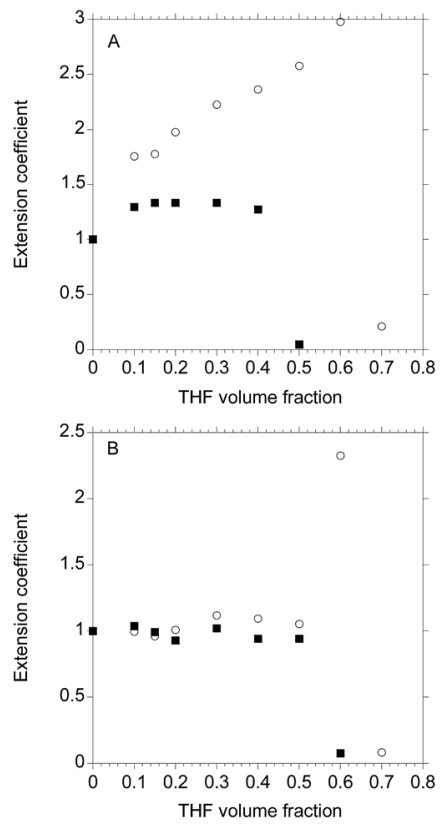

Fig. 4 Stability assessment by DLS in the presence of THF. $O$ Unreacted self-assembly; $\mathbf{\square}$ crosslinked self-assembly. (A) PEO-PCL 2000-2800; (B) PEO-PCL 5000-4000. 
strongly destabilized. In this case, the longer PCL block might bring a partial stabilization of the self-assembly, possibly owing to crystallization of the PCL core. Compared to other published results, ${ }^{20,28,51,67,68}$ the resistance of the reacted selfassemblies described here might appear lower. Indeed, the DLS results obtained in our study cannot guarantee a full resistance of the reacted objects to a high quantity of THF. However, even with this limitation, a marked difference between crosslinked and uncrosslinked systems was observed for PEO-PCL 2000-2800, ensuring that at least a partial crosslinking was obtained, which is consistent with ${ }^{1} \mathrm{H}$ NMR results in Table 2.

The resistance of PEO-PCL 2000-7000 self-assemblies towards increasing quantities of THF was also assessed and the results presented in ESI (Fig. S11 $\dagger$ ). As already mentioned, since these self-assemblies have a worm-like morphology, DLS analyses are only indicative. Basically, differences of behaviours were observed between unreacted and crosslinked systems, but their explanation would imply cross-examination with other techniques.

Beyond the stability of the self-assembly itself, the release rate of Pheo was also examined for the different selfassemblies by a dialysis follow-up at $37{ }^{\circ} \mathrm{C}$ (Fig. 5). Compared to un-reacted self-assemblies, both chain-end polymerized and crosslinked PEO-PCL 5000-4000 ones presented a close or only slightly slower release, which is different from most cases in the literature where crosslinking very often led to a slow release or even trapping of the

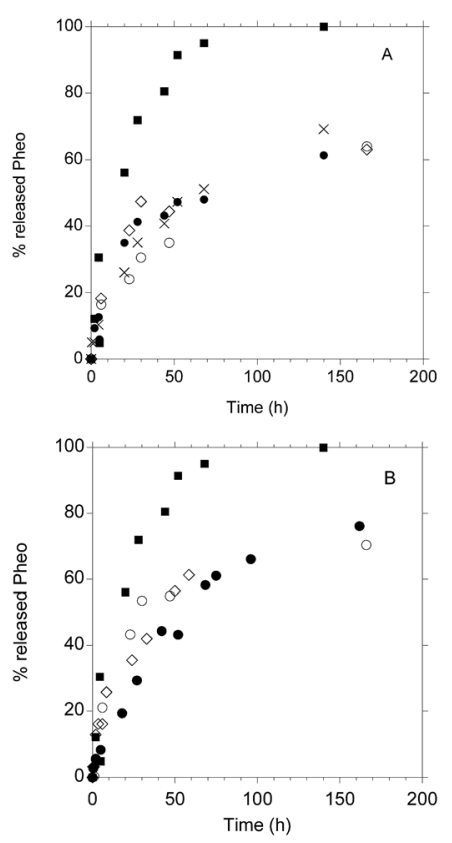

Fig. 5 Pheo release followed by dialysis in water at $37^{\circ} \mathrm{C}$ and [Pheo] $=10^{-6} \mathrm{M}$ using PEO-PCL self-assemblies. (A) PEO-PCL 5000-4000 and 2000-2800, free Pheophorbide, PEO-PCL 5000-4000, 0 chain-end polymerized PEO-PCL 5000-4000, $\diamond$ crosslinked PEOPCL 5000-4000, $\times$ PEO-PCL 2000-2800. (B) PEO-PCL 2000-7000; free Pheophorbide, PEO-PCL 2000-7000, O chain-end polymerized PEO-PCL 2000-7000, $\diamond$ crosslinked PEO-PCL 2000-7000. drug. ${ }^{26,39,41,66}$ As for PEO-PCL 2000-7000, the unreacted systems lead to a slightly higher release rate compared to chain end or crosslinked ones. In this case, partial blocking of the core might limit the penetration of Pheo in the core of the self-assembly.

\section{Pheo-loaded self-assemblies cytotoxicity and photocytotoxicity on HCT-116 2D cell culture}

The cytotoxicity of Pheo-loaded self-assemblies has been first evaluated in the dark on HCT-116 human colon cancer cells (Fig. 6). As expected, results did not show any statistically significant effect of the Pheo-loaded nanovectors nor one for Pheo alone without photoactivation. Two concentrations for the polymers were tested, namely $10 \mu \mathrm{M}$ and $100 \mu \mathrm{M}$, corresponding to the range used for the PDT tests. The Pheo-loaded PEOPCL 5000-4000 chain-end polymerized assembly was the only one which presented a slightly higher toxicity compared to the other ones with a statistical difference, but it remained low. In the subsequent experiments, the highest polymer concentration used was $50 \mu \mathrm{M}$ (corresponding to [Pheo] $=1.67 \mu \mathrm{M}$ ). Therefore, the slight dark toxicity for this system will be negligible.

Photocytotoxicity was assessed for Pheo-loaded PEO-PCL 2000-2800 self-assemblies on 2D HCT-116 cell culture. This showed an effect of the drug starting at $0.5 \mu \mathrm{M}$ of polymer, corresponding to a Pheo concentration of $0.0166 \mu \mathrm{M}$ with uncrosslinked micelles (Fig. 7), showing higher photocytoxic effect compared to Pheo alone. For chain-end polymerized or crosslinked systems, the effect was less pronounced than for uncrosslinked self-assemblies. This might be attributed to a retention effect of the drug by the crosslinked micelle as shown in different publications. ${ }^{16,17,19,25,34,38,45}$ One has to keep in

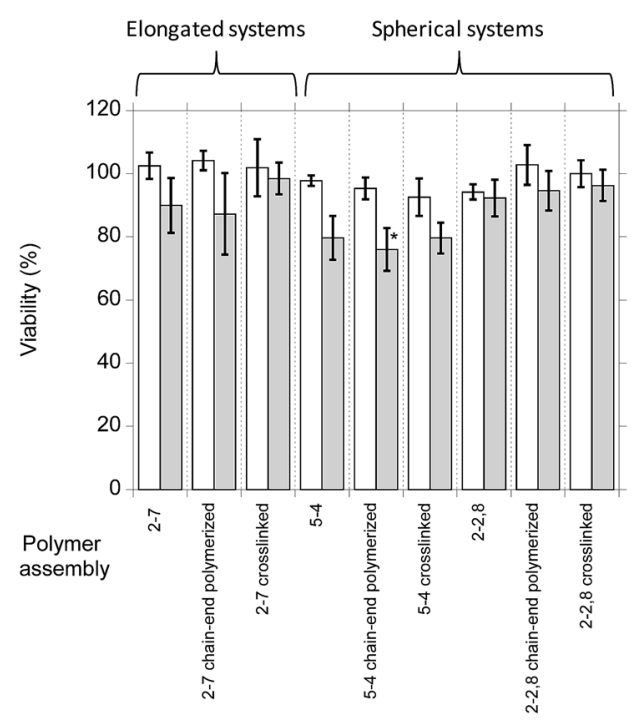

Fig. 6 Cytotoxicity of the Pheo-loaded self-assemblies ([Pheo]/ [polymer] $=1 / 30$ ) on 2D HCT-116 cell culture in the dark. Non-treated cell viability was set at $100 \%$. The columns $2-7,5-4$ and $2-2,8$ correspond to self-assemblies formed with acrylate functionalized polymers. 2-2,8, 5-4 and 2-7 respectively represents PEO-PCL 20002800, PEO-PCL 5000-4000 and PEO-PCL 2000-7000. White columns, [polymer] $=10 \mu \mathrm{M}$; grey columns, [polymer] $=100 \mu \mathrm{M}$. 
mind that the dialysis results presented above were performed in pure water and at a Pheo concentration of $1 \mu \mathrm{M}$, and indicated only a slightly lower release rate for chain-end polymerized micelles and an identical one for crosslinked systems. This configuration is similar to the $50 \mu \mathrm{M}$ polymer concentration in phototoxicity experiment (Fig. 7). Indeed, a $50 \mu \mathrm{M}$ polymer concentration corresponds to $1.67 \mu \mathrm{M}$ Pheo concentration and all systems led to complete cell death. For comparison, cytotoxicity and photocytotoxicity experiments were also carried out on normal human fibroblasts. These are presented in Fig. S12. $\dagger$ As expected, these showed that encapsulated Pheo exhibited no cytotoxicity but a high photocytotoxicity. The same trend of efficiency than in tumor cells was observed: unreacted $<$ chain end polymerized $<$ crosslinked.

\section{Photocytoxicity in 3D tumor spheroids}

In order to assess the PDT efficiency in an environment more relevant to in vivo situation compared to $2 \mathrm{D}$ cell culture, cytoand photocytotoxicity of the different systems were characterized on 3D multicellular tumor spheroids produced with HCT116 colon or FaDu head and neck cancer cells. Spheroids were incubated with the different systems, either loaded in Pheo or not $([$ polymer $]=100 \mu \mathrm{M}$, [Pheo] $=3.33 \mu \mathrm{M})$. Photoactivation protocol was performed following an already established procedure. $^{54}$

In order to analyze cell viability and death in spheroids, numerous methods could be used, from ATP quantification to microscopy, but a great number of them are destructive and have a large uncertainty. In our case, it was essential to assess the same spheroid evolution over time in order to be closer to reality. We chose an optical-based method to measure spheroid viability since it is non-destructive and has already been used in the literature for this purpose. ${ }^{69-71}$ Owing to the presence of coronas around the treated spheroids in this work, we felt it was important to certify this method reliability.

Two different certifications were performed. First, the human part of the methodology, which can be verified with measurements at different times, was correlated with a Pearson analysis;

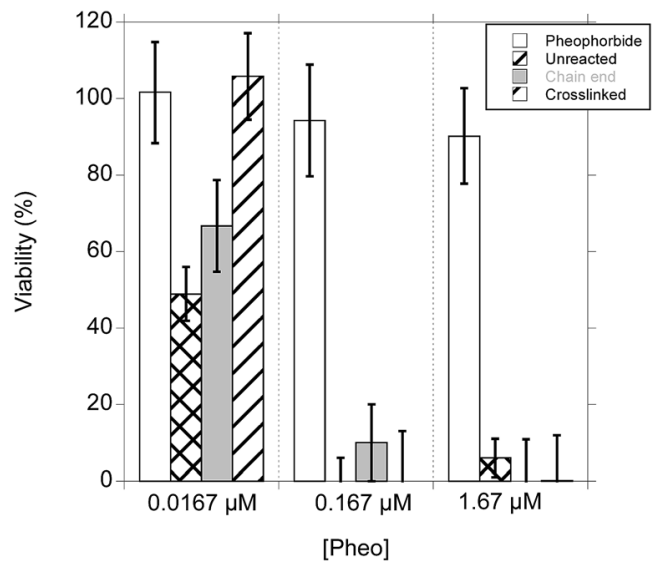

Fig. 7 Photocytotoxicity of Pheo alone and encapsulated in PEO-PCL 2000-2800 self-assemblies on 2D HCT-116 monolayer. as the data were parametric, Spearman's test was not necessary. Those correlations (Fig. S13†) showed a very good stability of the methodology over time with different data points.

The biological validity was evaluated in a second step. This was performed by the use of an ATP assay kit. 32 spheroids treated with three different Pheo-loaded nanovectors were thus analyzed in parallel by the optical method and by the ATP assay kit. The results are presented in Fig. 8 and S14. $\dagger$

Before doing any correlation, a check for any statistically significant differences was performed using Sidak multiple comparisons and multiple $t$ tests: none of them could find a statistical difference between the lines. Pearson correlation finally assessed the methodology. For FaDu spheroids, the results were very close for each method, owing to a very compact spheroid core enabling a good visualization of its limit. For HCT-116, the microscopic method slightly overestimated the living/dead cells ratio, due to a not as dense core. The evaluation of living cells by the optical microscopy method was thus validated. Typical optical microscopy images are shown in Fig. 9 and $\mathrm{S} 15 \dagger$ and analyzed in Fig. 10 and 11.

In order to apply PDT on spheroids of similar size, cell seeding density was adapted since FaDu cells proliferate more slowly than HCT-116. On these graphs, the initial size on day 0 was measured before the photoactivation process and photoactivations took place at days 0,1 and 2. For each experiment, the control condition consisted in a spheroid exposed to neither
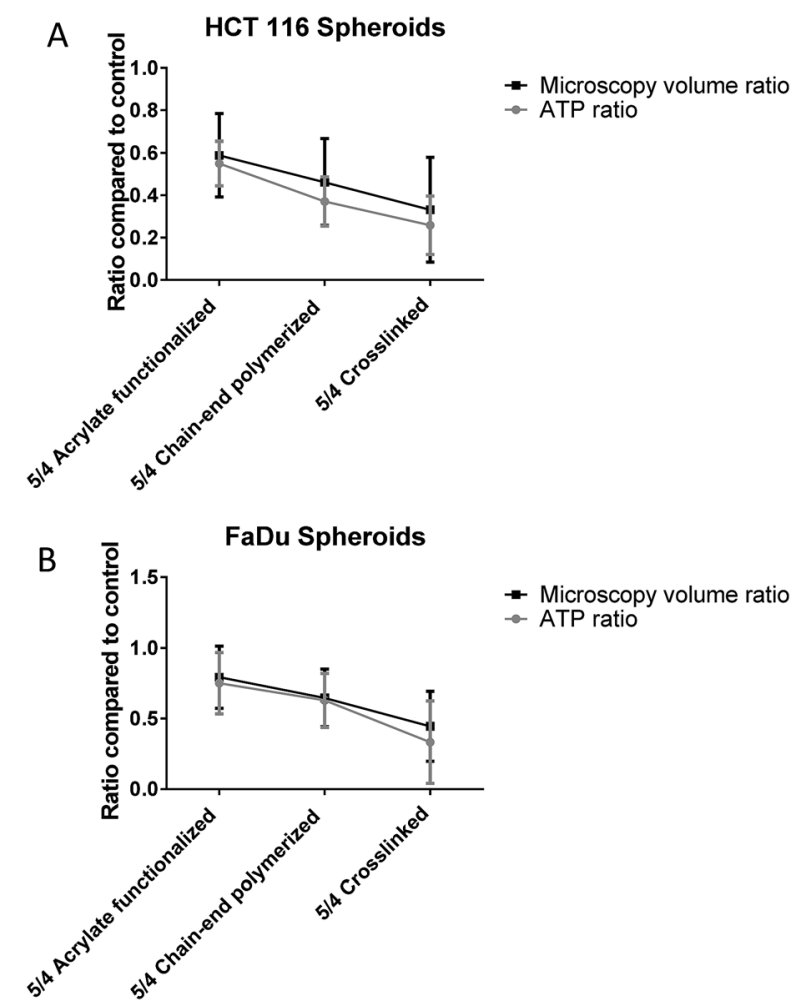

Fig. 8 Validation of optically-based microscopic measurements; comparison of viability evaluation by ATP-test and microscopy images analysis with confidence interval at 95\%. (A) HCT-116 spheroids; (B) FaDu spheroids. 
HCT 116 spheroids Acrylate functionalized Chain-end polymerized Crosslinked PEO-PCL 2000-2800

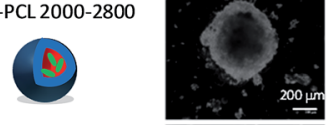

PEO-PCL $5000-4000$
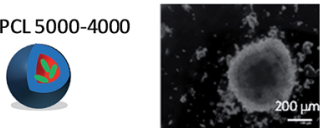

PEO-PCL 2000-7000
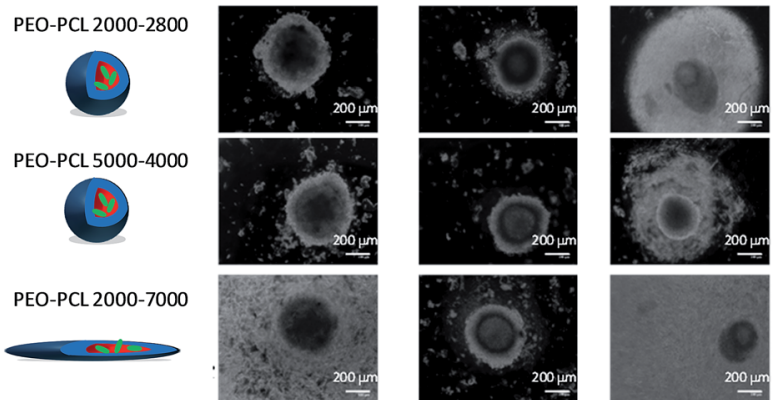

FaDu spheroids
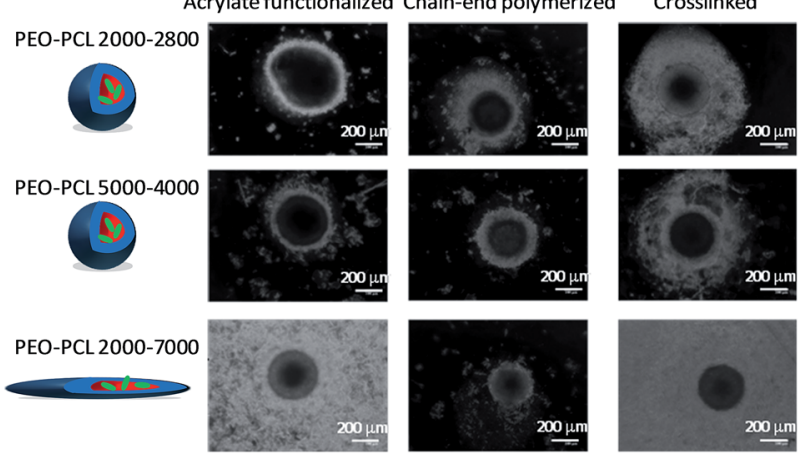

Fig. 9 PDT efficiency on HCT-116 and FaDu tumor spheroids. Spheroids were observed by wide-field optical microscopy. [Pheo] $=$ $3.33 \mu \mathrm{M}$.

self-assembly nor Pheo but submitted to the same photoactivations protocol than the other samples.

These experiments showed that Pheo alone had only a low PDT efficiency due to its tendency to aggregation in water (Fig. S16†). It remained inefficient for FaDu spheroids and became active on HCT-116 spheroids only on day 3 and 4 , leading at the best to the stabilization of the spheroid size and a relative size decrease of $35 \%$ compared to the control. Its encapsulation however led to a small PDT efficiency increase (Fig. 10 and 11) for acrylate functionalized micelles and to a much stronger one for the chain-end polymerized and crosslinked systems. Fig. 11 extracts the ratio between the treated spheroids surface compared to the control obtained on Fig. 10 at day 2 . Fig. S17† presents these data at day 4 . All acrylate functionalized micelles exhibited a limited PDT efficiency for FaDu spheroids at day 2, but this improved by day 4 with a relative decrease size of $c a$. $20 \%$ compared to the control. On HCT-116 spheroids, the efficiency was increased compared to the control even at day 2 and at day 4 , the relative decrease size compared to the control was $c a$. 50\%. Chain end polymerized nanovectors were able to stop spheroid growth for a short period of time, meaning that their PDT efficiency is higher than the one of the acrylate functionalized micelles. HCT-116 spheroids exhibited a relative size decrease of $c a .60 \%$ at day 2 for all systems. However, for FaDu speroids, it has to be noted that chain end polymerized PEO-PCL 2000-7000 was less efficient than other polymers (Fig. 11 and $\mathrm{S} 17 \dagger$ ). In this case, the spherical polymeric micelles are therefore more efficient than worm-like shapes. Finally, the strongest PDT effect was observed with crosslinked nanovectors which induced not only a stabilization of the spheroid size, but a marked decrease, meaning that tumor cells are highly impacted by the treatment. This is clearly visible on Fig. 11 and S17. $\dagger$ For HCT-116 spheroids, the relative size decrease was close to $80 \%$ at day 2 and approached $90 \%$ at day 4 . Here again, chain end polymerized PEO-PCL 2000-7000 system was less efficient at day 2; however, it regained efficiency at day 4. Finally, for FaDu spheroids, the relative size decrease compared to the control was close to $40 \%$ for all systems.

In order to compare the penetration of Pheo into the spheroids, two-photon microscopy experiments were carried out on PEO-PCL 5000-4000 and 2000-7000 systems, which were chosen to assess the two typical morphologies. Results are presented in Fig. 12. These showed that on FaDu systems, the crosslinked PEO-PCL 5000-4000 system exhibited the best penetration, compared to unreacted and chain end polymerized self-assemblies. For PEO-PCL 2000-7000, the results are not as clear, although the comparison of the stack of all images tends to point at a better penetration in the case of chain end polymerized and crosslinked assemblies. Comparing the case of FaDu to HCT-116 spheroids shows that the latter led to a better penetration.

\section{Discussion}

From these results, several points can be extracted and discussed.

First, regarding the synthesis of the crosslinked selfassemblies, the best result obtained in the absence of initiating molecule may be explained by different reasons. The principal one might be an unfavorable partition of the initiators between water and the self-assemblies. Indeed, Kissel and coll. showed that the best results were obtained when crosslinking was performed in solvent mixtures instead of pure water. ${ }^{61}$ This led to the swelling of the micelles and enabled the penetration of the initiators. This technique was further used by Jing and coll. ${ }^{62}$ However, we decided to avoid this procedure, since the limit between controlled and uncontrolled (leading to partial dissociation) swelling is difficult to adjust. Furthermore, the use of solvent mixture implies that the crosslinking is performed on micelles that may not have the same morphology. Another possible explanation suggested by Kissel and coll. for obtaining best results in the absence of initiators is linked to the semicrystallinity of poly(e-caprolactone) blocks, ${ }^{61}$ leading to a limited access and mobility of the reactive molecules inside the micelles. An alternative was given by Kataoka and coll. who used a more hydrophobic initiator than AIBN, namely azobisdimethylvaleronitrile. ${ }^{63}$ With our biological purpose in mind, we decided that limiting the addition of any new possibly toxic chemical compound was essential. Therefore, we chose the simplest protocol, although the yield might not be optimal.

Secondly, in the literature and contrary to our case, most studies include the drug during the self-assembly process. The advantage of such method is that the drug is clearly trapped 
Acrylate functionalized

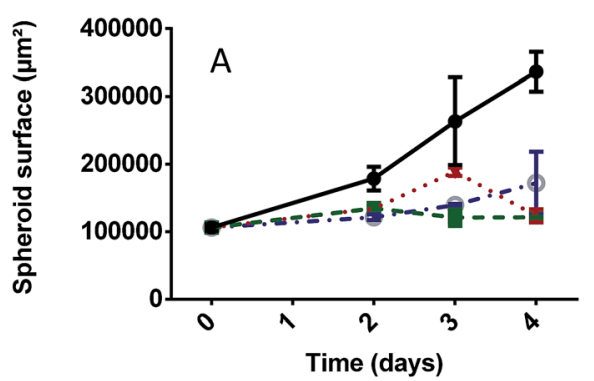

Chain-end polymerized

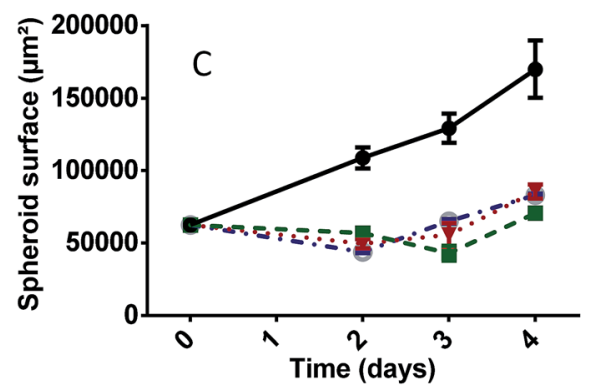

Crosslinked

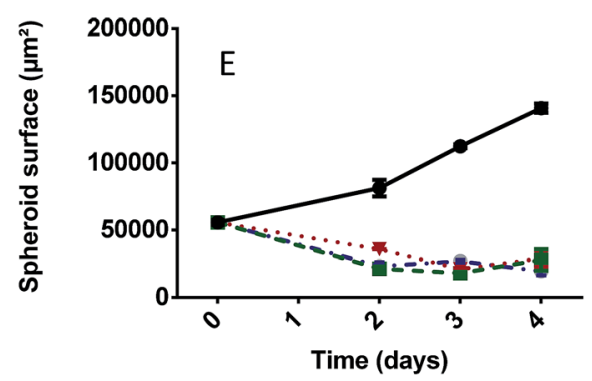

Acrylate functionalized

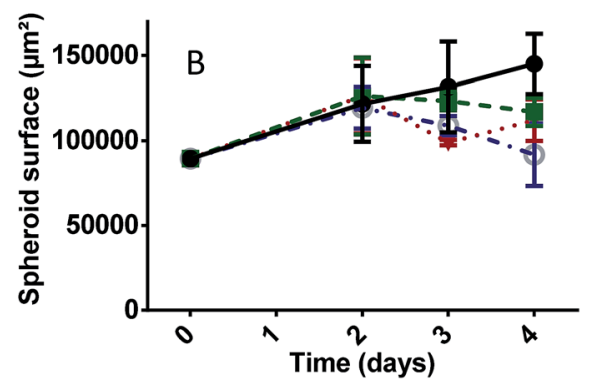

Chain-end polymerized

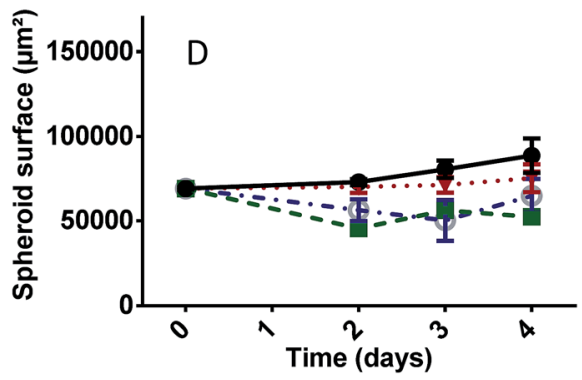

Crosslinked

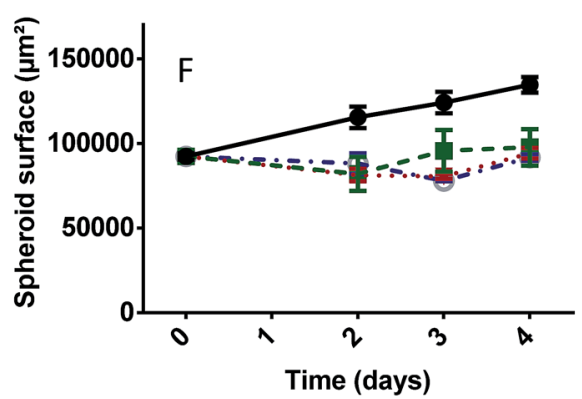

Fig. 10 Quantification of PDT efficiency by measuring viable spheroid surface on HCT-116 (A, C and E) and FaDu (B, D and F) cells. $\bullet$ Control without any polymer and any Pheo, O PEO-PCL 2000-2800, $\boldsymbol{\nabla}$ PEO-PCL 2000-7000, ם PEO-PCL 5000-4000. [Pheo] = 3.33 $\mu$ M.

inside the self-assembly and this is an asset to limit its early release. However, it is therefore present during the cross-linking reaction and a limitation of this strategy is the occurrence of side reactions of the drug during the crosslinking process possibly leading either to its partial degradation or its covalent bonding to the vector. In both cases, this would lead to lesser efficiencies for the therapeutic objective. An alternative method is to use polymer-drug conjugates with a labile bond. ${ }^{26,31}$ This ensures the encapsulation of a large quantity of the drug and enables a controlled release depending of the lability of the link. Only a few papers describe the encapsulation of the drug after formation and crosslinking of the nanovector. ${ }^{34,35,45,72}$ The advantage of such a strategy is that the drug remains intact and will be able to exit more easily. However, in some cases, this might lead to an early release. This is why the stability aspect was examined, in particular by dialyses follow-up, even if pure water was not the best medium to mimic the real application.
Thirdly, the main part to be discussed is the observed PDT efficiency. The major results are summarized in Table 4. The order for killing tumor cells grown in $3 \mathrm{D}$ is Pheo alone $<$ Pheo in unreacted micelles $<$ Pheo in chain-end polymerized systems $<$ Pheo in crosslinked systems. This is contrary to the behavior observed on 2D cell culture (Fig. 7), where all systems (except Pheo alone) led to a complete death for comparable concentrations. The behavior observed for low Pheo concentrations showed the reverse order for the nanovectors. This discrepancy between $2 \mathrm{D}$ and $3 \mathrm{D}$ is consistent with the trend observed in the literature for studies comparing in vitro and in vivo conditions for crosslinked polymer micelles. ${ }^{22,44,66,73}$ Indeed, the order of efficiency between uncrosslinked systems, free drug or crosslinked micelles has been described to change between in vitro and in vivo experiments. For instance, Hennink and coll. showed that crosslinked micelles were less efficient than free $\mathrm{DOX}^{73}$ or taxol ${ }^{44}$ in vitro but the reverse was observed for in vivo 


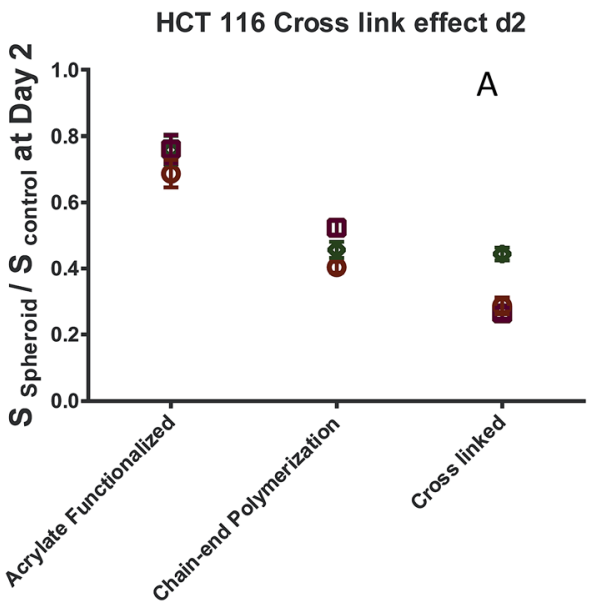

- PEO-PCL 2-7

口 PEO-PCL 5-4

- PEO-PCL 2-2.8

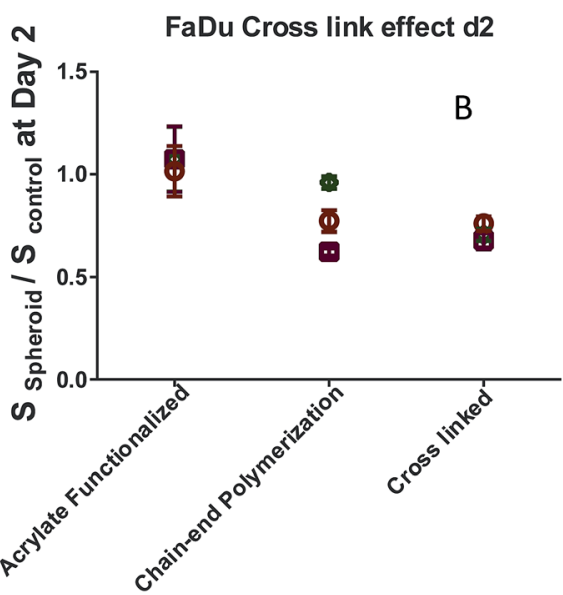

- PEO-PCL 2-7

口 PEO-PCL 5-4

- PEO-PCL 2-2.8

Fig. 11 PDT efficiency at day 2 of the different self-assemblies on HCT-116 (A) and FaDu (B) spheroids at day 2. S: surface of viable spheroid.

tests. When compared, crosslinked micelles are found as the most efficient system compared to uncrosslinked ones for in vivo experiments. ${ }^{22,31,66}$ Interestingly, the same trend was observed in Stenzel's recent study ${ }^{33,51}$ using pancreatic multicellular AsPc-1 tumor spheroids. This shows that this behavior is applicable to different cell lines and might be general. Stenzel and coll. explained this behavior by the fact that the drug encapsulated in crosslinked nanovectors is more protected from the environment and less prone to diffuse too quickly out of the vector. They have shown that diffusion of the encapsulated drug in the spheroid is a transcellular process in their case. They suggest that an early release of drug by the free drug or the uncrosslinked micelles leads to a formation of external layers of cells in apoptosis, which slow down or stop the progression of further drug to attack inner layers. Crosslinked systems, by slowing down the release, might therefore be on the right timescale to diffuse before releasing and killing the cells. Comparatively, in 2D cell cultures, crosslinking might act as a slowing down of the release compared to free or uncrosslinked systems. This does not mean that the same explanation is right for the cases presented here. Indeed, in our case, dialyses tests showed a similar release of Pheo regardless of the crosslinking

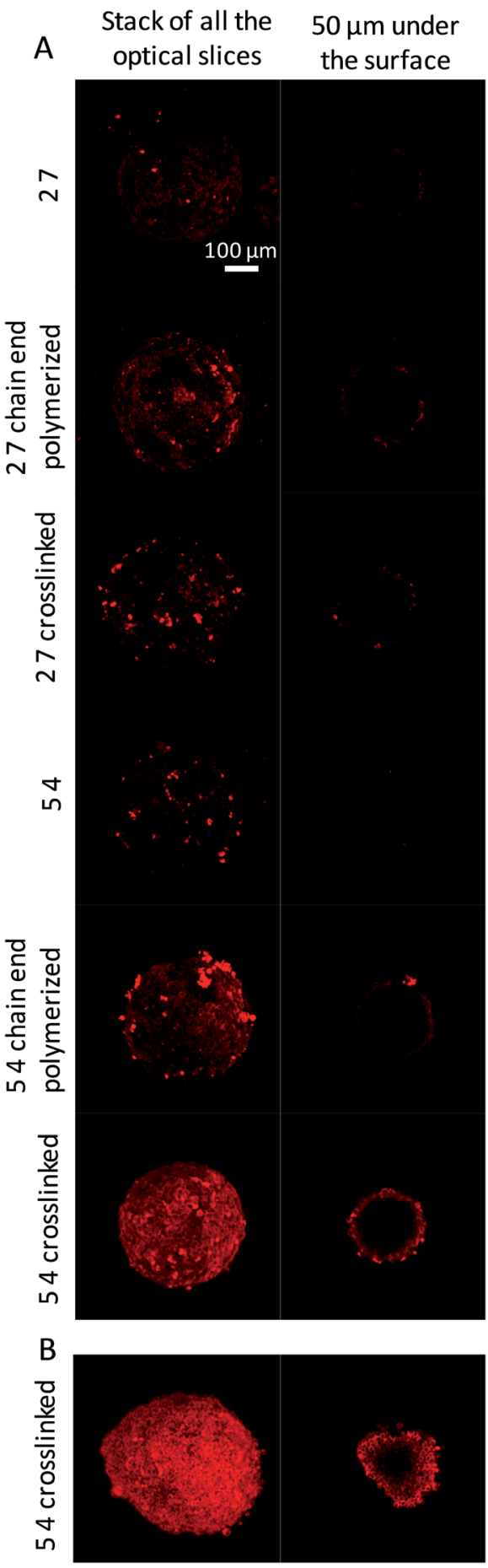

Fig. 12 Pheophorbide penetration in spheroids depending on the type of vectors. Pictures were obtained by two-photon microscopy on fresh spheroids incubated for 30 min with encapsulated Pheo. (A) FaDu spheroids. (B) HCT-116 spheroids.

of the vector, and even a small acceleration of the release for PEO-PCL 2000-7000 systems. However, these were performed in pure water and the release rate in biological media should be expected to be different.

Regarding the comparison between crosslinked and chainend polymerized systems, the observed PDT efficiency increase 
Table 4 Summary of PDT efficiency results

PDT efficiency

2D At low concentration: acrylate functionalized $>$ chain-end $>$ crosslinked $\approx$ Pheo alone At high concentration: acrylate

$3 \mathrm{D}$ functionalized $\approx$ chain-end $\approx$ crosslinked $>$ Pheo alone At high concentration: crosslinked $>$ chain-end $>$ acrylate functionalized $>$ Pheo alone

might appear as surprising owing to the similar release rate observed in dialyses tests. Once again, one should be cautious since these were performed in pure water. However, another essential point for the PDT efficiency is the quantity of photosensitizer which really penetrates into the cells. In order to rationalize the difference of PDT efficiency between crosslinked and chain-end polymerized vectors, a thorough study examining the penetration process of Pheo in each case should be performed, since earlier studies have shown that the load might enter with or without its cargo. ${ }^{74,75}$ A partial confirmation of the difference between chain end and crosslinked systems is however already given by the confocal images in Fig. 12.

The existence of discrepancies between 2D and 3D cell cultures is not very surprising and has already been reported in the literature. ${ }^{76,77}$ Based on our results, the 3D spheroid model is therefore expected to be a more reliable model, showing different effects that need to be taken into account for the real final application. In order to eradicate solid tumors, penetration of the drug as deeply as possible is essential; clearly $2 \mathrm{D}$ cell culture experiments cannot provide a reliable answer to this point.

Finally, a short comment on the shape effect of the selfassemblies is worthwhile. In the literature, worm-like vectors have been increasingly examined in the last ten years, following the early experiment of Discher on so called filomicelles. Influence of the shape has been assessed on different levels: the circulation in blood stream where margination occurred differently depending on the shape, ${ }^{78-82}$ biodistribution depending on the interaction with various tissue organs, ${ }^{59}$ and cell penetration following interaction with membranes. ${ }^{\mathbf{5 8 , 5 9 , 8 3 , 8 4}}$ Although many studies are based on particles with larger sizes than the ones presented here, a general trend seems to be that worm-like micelles exhibit a longer circulation time and a higher cell penetration. However, the explanation of this remains unclear and some exceptions have been described. ${ }^{\mathbf{8 3}}$ Clearly, more studies are needed to further classify each vector type. In our case, the worm-like self-assemblies were not observed to lead to enhanced PDT efficiency. At this point, we cannot point to a specific explanation. Vector's length, rigidity and surface groups are some of the known critical parameters involved in drug delivery efficiency, and this is also true for the shape.

\section{Conclusion}

As mentioned in the introduction, the aim of our work was twofold: first to compare the efficiency of crosslinked nanovectors in the field of photodynamic therapy (PDT), and secondly to examine the photocytotoxicity both on 2D and 3D cell cultures. Concerning the PDT standpoint of our work, the superiority of crosslinked nanovectors is demonstrated on both cell lines and both polymeric micelles and elongated assemblies. This follows results very recently obtained by Stenzel and coll. Clearly, such objects should therefore be considered as having a high potential for drug delivery in clinical applications. However, further experiments are needed to go beyond our observations and to finely analyze how crosslinked micelles induced an improved phototoxicity within spheroids. In particular, microscopic analyses of spheroids frozen sections and flow cytometry would help to qualitatively and quantitatively determine the distribution of the encapsulated drug within $3 \mathrm{D}$ cell assemblies.

We had chosen the three different polymers to characterize the polymer molecular weight influence for vectors having the same size, and the shape spherical/elongated type. Comparing PEO-PCL 2000-2800 to PEO-PCL 5000-4000 shows that both systems have a similar PDT activity. The molecular weight of the polymer does not lead to efficiency change, as long as the nano-vector keeps a close size and similar surface characteristics. As for the shape effect, PEO-PCL 2000-7000 self-assemblies were not observed in our case to be more efficient than spherical micelles. Regarding the 3D cell culture, the distinct and different results from the $2 \mathrm{D}$ to the $3 \mathrm{D}$ model show the great care that should be taken to study treatment efficiency with nanovectors. Results obtained in 2D do not necessarily correspond to those observed either on 3D or in vivo conditions. If $3 \mathrm{D}$ seems therefore a great improvement for testing, ${ }^{48-50}$ the question remains open whether it constitutes a good model for in vivo, the asset of spheroids being the possibility to limit sacrificing animals. This is indeed increasingly demanded by the population, as shown by the very recent European Citizen Initiative "Stop Vivisection", for which the European Union has just replied. ${ }^{\mathbf{8 5}}$ Finally, even if this was already used in biology, the fact that spheroid activity could be assessed by simple optical microscopy measurements should be kept in mind since this constitutes a much simpler method.

\section{Acknowledgements}

This work was funded by the French ANR P2N COPOPDT, MidiPyrénées region and University of Toulouse. Bruno Payré and Dominique Goudounèche from CMEAB are acknowledged for help on TEM experiments and Amélie CATALA for the help given on the statistic and reliability validation.

\section{References}

1 C. Allen, D. Maysinger and A. Eisenberg, Colloids Surf., B, 1999, 16, 3-27. 
2 A. Harada and K. Kataoka, Prog. Polym. Sci., 2006, 31, 949982.

3 N. Nishiyama and K. Kataoka, Pharmacol. Ther., 2006, 112, 630-648.

4 V. P. Torchilin, Pharm. Res., 2006, 24, 1-16.

5 M. G. Carstens, C. J. F. Rijcken, C. F. Van Nostrum and W. E. Henninck, in Multifunctional pharmaceutical nanocarriers, ed. V. P. Torchilin, Springer Science, New York, 2008, pp. 263-308.

6 K. Riehemann, S. W. Schneider, T. A. Luger, B. Godin, M. Ferrari and H. Fuchs, Angew. Chem., Int. Ed., 2009, 48, 872-897.

7 J. Shi, A. R. Votruba, O. C. Farokhzad and R. Langer, Nano Lett., 2010, 10, 3223-3230.

8 H. Cabral, N. Nishiyama and K. Kataoka, Acc. Chem. Res., 2011, 44, 999-1008.

9 J. Fang, H. Nakamura and H. Maeda, Adv. Drug Delivery Rev., 2012, 63, 136-151.

10 Y. Matsumura and H. Maeda, Cancer Res., 1986, 46, 63876392.

11 H. Maeda, Bioconjugate Chem., 2010, 21, 797-802.

12 C. F. van Nostrum, Soft Matter, 2011, 7, 3246-3259.

13 C. Deng, Y. Jiang, R. Cheng, F. Meng and Z. Zhong, Nano Today, 2012, 7, 467-480.

14 K. Emoto, Y. Nagasaki and K. Kataoka, Langmuir, 1999, 15, 5212-5218.

15 Y. Wu, W. Chen, F. Meng, Z. Wang, R. Cheng, C. Deng, H. Liu and Z. Zhong, J. Controlled Release, 2012, 164, 338-345.

16 M. Danquah, T. Fujiwara and R. I. Mahato, J. Polym. Sci., Part A: Polym. Chem., 2013, 51, 347-362.

17 I. Jiménez-Pardo, R. González-Pastor, A. Lancelot, R. Claveria-Gimeno, A. Velázquez-Campoy, O. Abian, M. B. Ros and T. Sierra, Macromol. Biosci., 2015, 15, 13811391.

18 Y.-C. Wang, Y. Li, T.-M. Sun, M.-H. Xiong, J. Wu, Y.-Y. Yang and J. Wang, Macromol. Rapid Commun., 2010, 31, 12011206.

19 L. Wu, Y. Zou, C. Deng, R. Cheng, F. Meng and Z. Zhong, Biomaterials, 2013, 34, 5262-5272.

20 X. Zhao and P. Liu, ACS Appl. Mater. Interfaces, 2015, 7, 166174.

21 Y. Li, S. Wang, D. Zhu, Y. Shen, B. Du, X. Liu and Y. Zheng, RSC Adv., 2015, 5, 20025-20034.

22 Y. Li, K. Xiao, J. Luo, W. Xiao, J. S. Lee, A. M. Gonik, J. Kato, T. A. Dong and K. S. Lam, Biomaterials, 2011, 32, 6633-6645.

23 R. Wei, L. Cheng, M. Zheng, R. Cheng, F. Meng, C. Deng and Z. Zhong, Biomacromolecules, 2012, 13, 2429-2438.

24 L. Gao, Q. Luo, Y. Wang, H. Du, X. Li, Z. Shen and W. Zhu, RSC Adv., 2014, 4, 4177-4180.

25 X. Hu, H. Li, S. Luo, T. Liu, Y. Jiang and S. Liu, Polym. Chem., 2013, 4, 695-706.

26 X. Hu, J. Tian, T. Liu, G. Zhang and S. Liu, Macromolecules, 2013, 46, 6243-6256.

27 K. Wang, Y. Liu, W.-J. Yi, C. Li, Y.-Y. Li, R.-X. Zhuo and X.-Z. Zhang, Soft Matter, 2013, 9, 692-699.

28 E. K. P. Kumar, R. V. Sondergaard, B. Windschiegl, K. Almdal and T. L. Andresen, J. Mater. Chem. B, 2014, 2, 6652-6659.
29 C. V. Synatschke, T. Nomoto, H. Cabral, M. Förtsch, K. Toh, Y. Matsumoto, K. Miyazaki, A. Hanisch, F. H. Schacher, A. Kishimura, N. Nishiyama, A. H. E. Müller and K. Kataoka, ACS Nano, 2014, 8, 1161-1172.

30 J. Wang, D. Zhao, Y. Wang and G. Wu, RSC Adv., 2014, 4, 11244-11250.

31 Z. Zhou, L. Li, Y. Yang, X. Xu and Y. Huang, Biomaterials, 2014, 35, 6622-6635.

32 H. Li, X. Zhang, X. Zhang, K. Wang, Q. Zhang and Y. Wei, J. Mater. Chem. B, 2015, 3, 1193-1197.

33 H. Lu, R. H. Utama, U. Kitiyotsawat, K. Babiuch, Y. Jiang and M. H. Stenzel, Biomater. Sci., 2015, 3, 1085-1095.

34 Y. Li, Y. Shen, S. Wang, D. Zhu, B. Du and J. Jiang, RSC Adv., 2015, 5, 30380-30388.

35 Q. Fu, J. Xu, K. Ladewig, T. M. A. Henderson and G. G. Qiao, Polym. Chem., 2015, 6, 35-43.

36 G. Kocak and V. Bütün, Colloid Polym. Sci., 2015, 1-10.

37 J. Xu, F. Zeng, H. Wu, C. Hu and S. Wu, Biomacromolecules, 2014, 15, 4249-4259.

38 S. Wu, H. Kuang, F. Meng, Y. Wu, X. Li, X. Jing and Y. Huang, J. Mater. Chem., 2012, 22, 15348-15356.

39 L. Yan, L. Yang, H. He, X. Hu, Z. Xie, Y. Huang and X. Jing, Polym. Chem., 2012, 3, 1300-1307.

40 Y. Han, J. Li, M. Zan, S. Luo, Z. Ge and S. Liu, Polym. Chem., 2014, 5, 3707-3718.

41 Y. Shi, C. F. van Nostrum and W. E. Hennink, ACS Biomater. Sci. Eng., 2015, 1, 393-404.

42 Y. Zhang, C. Wang, Y. Huang, H. Yan and K. Liu, Eur. Polym. J., 2015, 68, 104-114.

43 P. Rajdev, D. Basak and S. Ghosh, Macromolecules, 2015, 48, 3360-3367.

44 Y. Shi, R. van der Meel, B. Theek, E. Oude Blenke, E. H. E. Pieters, M. H. A. M. Fens, J. Ehling, R. M. Schiffelers, G. Storm, C. F. van Nostrum, T. Lammers and W. E. Hennink, ACS Nano, 2015, 9, 3740-3752.

45 J. Chen, J. Ouyang, J. Kong, W. Zhong and M. M. Xing, ACS Appl. Mater. Interfaces, 2013, 5, 3108-3117.

46 M. A. Schwartz and C. S. Chen, Science, 2013, 339, 402-404.

47 F. Hirschhaeuser, H. Menne, C. Dittfeld, J. West, W. MüllerKlieser and L. A. Kunz-Schughart, J. Biotechnol., 2010, 148, 315.

48 C. M. Nelson and M. J. Bissell, Annu. Rev. Cell Dev. Biol., 2006, 22, 287-309.

49 F. Pampaloni, E. G. Reynaud and E. H. Stelzer, Nat. Rev. Mol. Cell Biol., 2007, 8, 839-845.

50 L. G. Griffith and M. A. Swartz, Nat. Rev. Mol. Cell Biol., 2006, 7, 211-224.

51 A. W. Du, H. Lu and M. H. Stenzel, Biomacromolecules, 2015, 16, 1470-1479.

52 S. B. Brown, E. A. Brown and I. Walker, Lancet Oncol., 2004, 5, 497-508.

53 J. W. Miller, et al., Arch. Ophtalmol., 1999, 117, 1161-1173.

54 L. Gibot, A. Lemelle, U. Till, B. Moukarzel, A. F. Mingotaud, V. Pimienta, P. Saint-Aguet, M. P. Rols, M. Gaucher, F. Violleau, C. Chassenieux and P. Vicendo, Biomacromolecules, 2014, 15, 1443-1455. 
55 K. Knop, A. F. Mingotaud, N. El-Akra, F. Violleau and J. P. Souchard, Photochem. Photobiol. Sci., 2009, 8, 396-404.

56 U. Till, M. Gaucher-Delmas, P. Saint-Aguet, G. Hamon, J.-D. Marty, C. Chassenieux, B. Payré, D. Goudounèche, A. F. Mingotaud and F. Violleau, Anal. Bioanal. Chem., 2014, 406, 7841-7853.

57 J. Ehrhart, A.-F. Mingotaud and F. Violleau, J. Chromatogr. A, 2011, 1218, 4249-4256.

58 R. Vacha, F. J. Martinez-Veracoechea and D. Frenkel, Nano Lett. , 2011, 11, 5391-5395.

59 M. B. Fish, A. J. Thompson, C. A. Fromen and O. EniolaAdefeso, Ind. Eng. Chem. Res., 2015, 54, 4043-4059.

60 H. Cabral and K. Kataoka, Sci. Technol. Adv. Mater., 2010, 11, 014109.

61 X. Shuai, T. Merdan, A. K. Schaper, F. Xi and T. Kissel, Bioconjugate Chem., 2004, 15, 441-448.

62 X. Hu, X. Chen, J. Wei, S. Liu and X. Jing, Macromol. Biosci., 2009, 9, 456-463.

63 M. Iijima, Y. Nagasaki, T. Okada, M. Kato and K. Kataoka, Macromolecules, 1999, 32, 1140-1146.

64 C. J. Rijcken, C. J. Snel, R. M. Schiffelers, C. F. van Nostrum and W. E. Hennink, Biomaterials, 2007, 28, 5581-5593.

65 K. Emoto, Y. Nagasaki and K. Kataoka, Langmuir, 1999, 15, 5212-5218.

66 R. Yang, F. Meng, S. Ma, F. Huang, H. Liu and Z. Zhong, Biomacromolecules, 2011, 12, 3047-3055.

67 F. Jia, Y. Wang, H. Wang, Q. Jin, T. Cai, Y. Chen and J. Ji, Polym. Chem., 2015, 6, 2069-2075.

68 C. Chang, H. Dan, L.-P. Zhang, M.-X. Chang, Y.-F. Sheng, G.-H. Zheng and X.-Z. Zhang, J. Appl. Polym. Sci., 2015, 132, DOI: $10.1002 /$ app.41752.

69 H. Hirschberg, C.-H. Sun, B. J. Tromberg and S. J. Madsen, J. Neuro-Oncol., 2002, 57, 1-7.

70 M. Vinci, S. Gowan, F. Boxall, L. Patterson, M. Zimmermann, C. Lomas, M. Mendiola, D. Hardisson and S. A. Eccles, BMC Biol., 2012, 10, 29.

71 J. Friedrich, C. Seidel, R. Ebner and L. A. Kunz-Schughart, Nat. Protoc., 2009, 4, 309-324.
72 J.-H. Kim, K. Emoto, M. Iijima, Y. Nagasaki, T. Aoyagi, T. Okano, Y. Sakurai and K. Kataoka, Polym. Adv. Technol., 1999, 10, 647-654.

73 M. Taleli, M. Iman, A. K. Varkouhi, C. J. F. Rijcken, R. M. Schiffelers, T. Etrych, K. Ulbrich, C. F. van Nostrum, T. Lammers, G. Storm and W. E. Henninck, Biomaterials, 2010, 31, 7797-7804.

74 P. Xu, E. Gullotti, L. Tong, C. B. Highley, D. R. Errabelli, T. Hasan, J.-X. Cheng, D. S. Kohane and Y. Yeo, Mol. Pharm., 2009, 6, 190-201.

75 R. Kerdous, F. Sureau, A. Bour and S. Bonneau, Int. J. Pharm., 2015, 495, 750-760.

76 K. A. Fitzgerald, M. Malhotra, C. M. Curtin, F. G. O'Brien and C. M. O'Driscoll, J. Controlled Release, 2015, 215, 39-54.

77 I. Levinger, Y. Ventura and R. Vago, Adv. Cancer Res., 2014, 121, 383-414.

78 R. D'Apolito, G. Tomaiuolo, F. Taraballi, S. Minardi, D. Kirui, X. Liu, A. Cevenini, R. Palomba, M. Ferrari, F. Salvatore, E. Tasciotti and S. Guido, J. Controlled Release, 2015, 217, 263-272.

79 N. Doshi, B. Prabhakarpandian, A. Rea-Ramsey, K. Pant, S. Sundaram and S. Mitragotri, J. Controlled Release, 2010, 146, 196-200.

80 F. Gentile, C. Chiappini, D. Fine, R. C. Bhavane, M. S. Peluccio, M. M.-C. Cheng, X. Liu, M. Ferrari and P. Decuzzi, J. Biomech., 2008, 41, 2312-2318.

81 R. Toy, E. Hayden, C. Shoup, H. Baskaran and E. Karathanasis, Nanotechnology, 2011, 22, 115101.

82 K. Vahidkhah and P. Bagchi, Soft Matter, 2015, 11, 20972109.

83 J.-M. Williford, J. L. Santos, R. Shyam and H.-Q. Mao, Biomater. Sci., 2015, 3, 894-907.

84 T. Yue, Y. Xu, M. Sun, X. Zhang and F. Huang, Phys. Chem. Chem. Phys., 2016, 18, 1082-1091.

85 http://ec.europa.eu/citizens-initiative/public/initiatives/ finalised/answered, Answer of EU to ECI Stop vivisection C, 2015, 3773 final, accessed 3rd, June 2015. 